\title{
pro.posições
}

$e$-ISSN 1980-6248

DOSSIÊ: Homeschooling e o Direito à Educação

\section{O homeschooling e a crítica à escola: hibridismos e (des)continuidades educativas}

\section{Homeschooling and the criticism of school: hybridisms and educational (dis)continuities}

\author{
Álvaro Manuel Chaves Ribeiro ${ }^{(i)}$ \\ José Palhares (ii)
}

\begin{abstract}
(i) Universidade do Minho, Braga, Portugal. alvarochaves.ribeiro@gmail.com
(ii) Universidade do Minho, Braga, Portugal. jpalhares@ie.uminho.pt.
\end{abstract}

Resumo: Desde os anos 1960, o homeschooling apresenta dinâmicas de crescimento atualizadas nos diagnósticos da crise do capitalismo e dos sistemas educativos. Por ser praticado por famílias próximas do progressismo libertário, do cristianismo conservador ou de outras inspirações axiológicas, a abordagem investigativa presente neste texto pressupôs romper com uma visão unívoca e alheia à sua diversidade e aos diferentes graus de (in)formalidade dos quotidianos educativos de crianças e de jovens que caracterizam este fenómeno educativo. Procura-se captar as especificidades do ensino doméstico (ED) em Portugal e a sua crescente expressão social e educacional e reflete-se sobre os sentidos das aprendizagens que ele encerra. Conclui-se que o ED parece ser contrário aos horizontes formativos da criança segundo o interesse da sociedade, sendo omisso sobre o seu papel na emancipação dos sujeitos. Confrontam-se a escola e o seu modo de funcionamento a partir do racional do ED, à procura de novas epistemologias e de novas linhas de pesquisa.

Palavras-chave: ensino doméstico, aprendizagens (não-formais e informais), educação familiar, dinâmicas de escolarização, subjetividades 


\section{pro.posıções}

Abstract: Since the 1960s, homeschooling has shown growth dynamics updated by the diagnosis of the crisis of capitalism and of educational systems. Because it is practiced by families close to libertarian progressivism, conservative Christianity, or other axiological inspirations, this paper's approach sought to break with a univocal conception alien to its diversity and to the different degrees of (in)formality of the children's and young people's educational daily lives inherent to this educational practice. Therefore, this paper seeks to understand the specificities of Portuguese bomeschooling and its increasing social and educational expression, and to reflect on the meanings of the learning it entails. Being unclear about its role on the emancipation of the subjects, bomeschooling seems to be contrary to the educational horizons of the child according to the interests of the whole society. This paper confronts school and its way of functioning with the homeschooling rationale in order to search for new epistemologies and new lines of research.

Keywords: homeschooling, non-formal and informal learning, family education, dynamics of mass schooling, subjectivities

\section{Introdução}

Temos vindo a ensaiar a hipótese de o ensino doméstico configurar-se como um novo movimento social (Ribeiro, 2010, 2015), talvez mais renovado do que novo; ou não fosse este fenómeno educacional uma experiência contemporânea de recuperação da matriz original de educação antes da disseminação da moderna forma escolar (Vincent, Lahire \& Thin, 1994) do ensino de massas. Conquanto esse debate não ganhe espessura reflexiva, é-nos dado a observar uma crescente contestação ao capitalismo moderno, às suas lógicas produtivistas e burocráticas, cuja expressão entre os homeschoolers se materializa na veemente crítica à escola e ao Estado. A emergência de novos temas e agentes, agora menos centrados na transformação das condições e das contradições sociais e mais deslocados para valores "estruturantes das consciências e das identidades dos indivíduos e dos grupos” (Fernandes, 1993, p. 811), inscreve-se num processo de "afirmação da subjetividade sobre a cidadania", em que os novos movimentos sociais lutam por uma emancipação não tanto "política mas antes pessoal, social e cultural” (Santos, 1994, p.225).

A reivindicação "de um atributo positivo" (Touraine, 1999, p. 74), em nome do qual germina o movimento homeschooling, trouxe para a ordem do dia a discussão pública e o debate político de problemas educacionais, latentes ou pura e simplesmente ignorados (Kunzman, 2009; Ribeiro, 2015; Stevens, 2001). Na agenda das famílias envolvidas problematiza-se se a escola sabe que lida com seres humanos, que têm vida, sentimentos, emoções, necessidades, 


\section{pro.posições}

$e$-ISSN 1980-6248

vontades, aspirações individuais, sonhos e quereres diferentes dos outros; que são únicos e querem ser tidos em contextos educativos que os desenvolvam na sua plenitude. Questiona-se ainda se a escola se lembra da real existência dos educandos, que devem ser alvo de um tratamento centrado na sua individualidade e não vistos como seres doutrináveis em massa. Por exemplo, num nosso trabalho anterior (Ribeiro, 2010), quando questionadas sobre os aspetos que mais rejeitam da escola, as famílias isolam uma relação sistémica entre o mundo a fingir, a despersonalização pedagógica e o sedentarismo intelectual que limita o crescimento das capacidades dos alunos, sobretudo quando este ocorre em espaços murados (Ribeiro, 2010). Gatto $(2005,2010)$ traduz este pensamento quando diz que a escola de massas, em vez de providenciar originalidade, variedade, liberdade, confiança, criatividade, pensamento crítico e construção do sujeito independente, através do monopólio governamental, tem produzido adultos indiferentes, sem curiosidade, com reduzido sentido de futuro, a-históricos, materialistas, passivos e tímidos diante de novos desafios. Nesta ótica, a escola removeria das crianças qualquer possibilidade de terem um papel ativo na vida comunitária, sendo essa obnubilada pelo peso da estrutura social burocrática e hierárquica.

O ensino doméstico é um projeto coletivo com história, dimensão organizacional e estruturas de apoio, portador de novos valores, práticas sociais, estilos de vida, maneiras diferentes de encarar a educação e certos aspetos da existência social (Ribeiro, 2010, 2015). O seu crescimento tem sido favorecido pela atitude dos praticantes que, ao mesmo tempo em que lutam pela normalização do movimento (Mayberry, Knowles, Ray, \& Marlow, 1995), evitam posturas sociais revolucionárias de mudança social total (Collom \& Mitchell, 2005). Pretendem ser uma alternativa que, enquanto vai mudando individualmente os pais e os filhos (os alunos), "estabelecem sistemas sociais de pequena escala para remediar a doença da sociedade em geral" (Kanter, 1972, p. 62) e permite "viver de acordo com o seu próprio sistema de valores fora das instituições socialmente estabelecidas" (Appelbaum \& Chambliss, 1995, p. 544). Uma alternativa comunitária, muito próxima da aceção de Zablocki (1980). 


\section{pro.posições

\section{Famílias que ensinam no espaço doméstico: disjunções sociais e analíticas}

A nossa experiência investigativa sobre o ensino doméstico em Portugal tem evidenciado que as famílias envolvidas têm vindo a trilhar um caminho educativo, cognitivo e ideológico que permita repensar os "paradigmas sociais e culturais preexistentes como parte de uma política de identidade" (Torres, 2003, p. 78). Elegendo a educação como uma estratégiachave, o ensino doméstico em Portugal prefigura uma mobilização mais segmentada e agregadora de aderentes pluri-ideológicos que visam afirmar as suas identidades sociais e melhorar a sua qualidade de vida, inspirando-se em valores não materialistas e universalistas.

Os termos analíticos deste estudo sobre o ensino doméstico, ao assumirem a segmentação e a especificidade sociológica entre os praticantes, sejam eles progressistaslibertários, crentes cristãos ou de uma definição menos polarizada, permitem-nos afirmar, na linguagem de Bourdieu (1998), a existência de campos de relações sociais relativamente autónomos uns dos outros, embora com homologias estruturais entre elas. Por isso, em função dos subsistemas organizativos que se têm desenvolvido através das práticas quotidianas destas famílias, as homologias entre os praticantes podem significar, na linha de Luhmann (1995), uma crescente diferenciação entre os sistemas societais e os sistemas de interação interfamiliar, ficando cada um deles progressivamente menos dependente dos constrangimentos do outro. À luz de Habermas (1992), parece haver como que uma disjunção entre o mundo vivido de quem pratica e não pratica, e entre quem pratica entre si.

Nesse ambiente disjuntivo, o ensino doméstico tem prevalecido como um projeto educacional cuja tendência não mostra qualquer sinal de desvanecimento (Bendell, 1994; Kunzman, 2009). A sua cristalização como fenómeno social e educacional nas últimas cinco décadas impede-nos de o catalogar como um mero episódio, dependente de vontades circunstanciais e conjunturais de determinados segmentos sociais. À medida que novos militantes entram para este movimento, não se tem notado uma volatilidade dos compromissos dos pioneiros, seja entre os crentes cristãos conservadores, seja mesmo entre os mais radicais progressistas-libertários (de tipo unschooling).

A diferenciação e a instabilidade das condições de socialização (Lahire, 2003, 2005), tal como o declínio do "programa institucional" (Dubet, 2002) nas atuais sociedades ocidentais, 


\section{pro.posıções}

parecem não ter abalado muito a matriz axiológica dos praticantes de ensino doméstico, particularmente no que diz respeito à fidelidade nas crenças pedagógicas de John Holt e do protestantismo conservador do casal Moore (Ribeiro, 2010, 2015).

De modo a facilitar a leitura da realidade, temos vindo a ensaiar a construção de uma tipologia das famílias praticantes do ensino doméstico, alicerçada, sobretudo, nas suas racionalidades de base. As famílias saber tornar-se são crentes cristãs conservadoras. De enfoque racional cristão, o exercício do poder é dirigido pelos pais no diagnóstico, na transmissão, na exercitação, na consolidação e na avaliação de um saber determinado pela integração de uma narrativa que os transcende. O saber tornar-se pressupõe uma noção de subjetividade que conhece e interioriza os princípios, as normas e as regras familiares segundo dinâmicas de autoridade, disciplina, obediência e respeito pela hierarquia. Contudo, uma vez que os pais também estão em constante desenvolvimento espiritual, não se consideram experts. Pelo que o enfoque racionalista não será impositivo, mas antes contínua e mutuamente construtivo, em função da ampliação e do aprofundamento das aprendizagens da narrativa de base e a partir dela (Ribeiro, 2015).

Adotando um ponto de vista quase antagónico, as famílias saber ser, ideologicamente progressista-libertárias, concebem uma pedagogia de tipo humanista, centrada na criança como um agente ativo no seu próprio processo de educação e socialização. Os processos educativos decorrem de práticas parentais apoiadas na comunicação, na confiança incondicional, na abertura e no respeito pela individualidade das crianças, emergindo num ambiente informal, de modo a favorecer-se o desenvolvimento e a autoaprendizagem, no qual os adultos se prefiguram mais como observadores do que como protagonistas na orientação do sentido das aprendizagens. A reunião e a partilha são práticas constitutivas do seu modo de afirmação, não raras vezes apoiando-se nas atuais tecnologias da informação e da comunicação para promoção das suas mensagens. Parecem ser, na esteira de Stevens (2001), espíritos livres e sociais renegados, com um pé na contracultura, muito embora, por força do seu racional de ação e dos valores que pautam o seu quotidiano, tenhamos dúvidas de que possam entrar nas "categorias sociais excluídas que se querem ver representadas socialmente", para usar aqui o ponto de vista de Melucci (1996, pp. 104-105) a propósito da complexidade dos atuais movimentos sociais.

No que concerne às orientações educativas e de socialização, encontramos, num plano mais intermédio, uma configuração familiar de tipo simbiosinergético, na aceção de Bertand e 


\section{pro.posıções}

Valois (1994), e que aqui passaremos a denominar de famílias saber estar com. Essas famílias colocam no centro a criança e os pais/família, ambos aprendendo por reciprocidade e se desenvolvendo como parceiros na partilha de saberes e decisões que lhes dizem mutuamente respeito. Funcionando segundo um modelo decisório do tipo mutualista não hierárquico, dizem respeitar os direitos individuais da criança e os coletivos familiares, através da negociação, da valorização e aceitação das diferenças e da ajuda mútua.

Cientes da artificialidade subjacente a qualquer construção tipológica, este exercício classificatório, serve, contudo, para ilustrar uma diversidade de racionalidades que compõe o movimento homeschooling, a maior parte das vezes ignorado na sua densidade sociológica, como se este fenómeno educacional se encerrasse na sua singularidade. Além disso, e tomando emprestadas as cautelas metodológicas apontadas por Kennedy (2008), quando diz que "qualquer contacto com os praticantes vai revelar muito mais complexidade e diversidade do que pode eventualmente estar contidos em dois, quatro ou uma dúzia de classificações” (p.11), convém ter presente um certo ajustamento das razões justificativas para a entrada no ensino doméstico, pois, à medida que essa experiência decorre, tende-se a encontrar nas famílias um outro tipo de motivações. Por conseguinte, o ensino doméstico inscreve a educação e a formação de crianças e jovens em matrizes axiológicas cujas aprendizagens se fazem segundo diferentes graus de (in)formalidade.

Pretendemos, seguidamente, dar expressão às várias perspetivas de aprendizagem que o ensino doméstico em Portugal encerra, sustentados numa abordagem de pendor qualitativo que buscou compreender as epistemologias educativas das famílias, no que se refere particularmente aos papéis do educador e do educando, aos dispositivos didático-pedagógicos e a sua articulação com as diversas mundividências que sustentam tais epistemologias no quotidiano.

Antes, porém, revelar-se-á pertinente apresentarmos os contornos em que se têm apoiado as estratégias de disseminação do ideário homeschooling na sociedade portuguesa, assim como a disposição do espaço social e cultural que o configura, tendo por base a caracterização sociográfica das famílias aderentes a este fenómeno educacional. 


\section{pro.posıções

\section{Dimensões contextuais e socioculturais do ensino doméstico em}

\section{Portugal}

Os dados e a reflexão que a seguir encadearemos resultam de um projeto de pesquisa de longa duração que passou pela apresentação de uma dissertação de mestrado (Ribeiro, 2010) e culminou recentemente na defesa da tese de doutoramento (Ribeiro, 2016), ambas realizadas na Universidade do Minho. Por terem sido conduzidas no âmbito da área científica da Organização e Administração Escolar, a nossa preocupação investigativa cedo passou pela necessidade de olhar a escola a partir de pontos de vista exteriores, sobretudo por aqueles que adotaram uma postura crítica e de rutura com esta instituição educativa. Independentemente da área disciplinar que orientou a aproximação teórico-empírica ao terreno, cedo se tornou claro que o bomeschooling instigava a uma abordagem sociológica inversa: seria possível estudar a escola e os correlativos processos de escolarização de massas a partir das margens ou das periferias do sistema? Que problematizações e "olhares" poderiam emergir pelo acercamento à irredutibilidade de pontos de vista veiculados no e pelo movimento em relação à universalidade da educação escolar? Não estaria a prevalecer na opinião pública uma visão unívoca, e de superfície, sobre um fenómeno educacional denso e heterogéneo, quando a dispersão dos indícios convidava o pesquisador a mergulhar numa realidade matizada por múltiplas racionalidades e (des)continuidades?

A proximidade da rede de interconhecimento constituída por praticantes do ensino doméstico foi, porventura, uma alavanca à operacionalização empírica da pesquisa, muito embora esta se tenha processado por aproximações sucessivas, dado o desconhecimento, à partida, do universo de pessoas envolvidas. Desde logo fomos tomando consciência da capilaridade deste fenómeno e dos correlativos vasos comunicantes, pois, tal como a metáfora da bola de neve, dia após dia íamos tomando conta do número crescente de homeschoolers. Aliás, várias investidas junto do Ministério da Educação português nunca se revelaram frutíferas na obtenção de estatísticas fiáveis. A informação constante na Tabela 1 é lacunar e pecará sempre por defeito. Não obstante as imprecisões, é possível constatar um sentido crescente no número de alunos em ensino doméstico, sendo de sublinhar o acréscimo substancial observado no ano letivo de 2013-2014. 


\section{pro.posıções \\ $e$-ISSN 1980-6248}

Tabela 1: Número de alunos matriculados em ensino doméstico entre 2006-2014

\begin{tabular}{|l|l|l|l|l|l|l|l|}
\hline Ano & Ano & Ano & Ano & Ano & Ano & Ano & Ano \\
letivo & letivo & letivo & letivo & letivo & letivo & letivo & letivo \\
$2006-07$ & $2007-08$ & $2008-09$ & $2009-10$ & $2010-11$ & $2011-12$ & $2012-13$ & $2013-14$ \\
\hline 6 & 44 & 67 & 82 & 97 & -- & 76 & 338 \\
\hline
\end{tabular}

Fonte: Adaptado de Ribeiro (2015)

Mais recentemente, um artigo (Gonçalves, Barra, \& Rosa, 2016) publicado no jornal semanário Expresso dava conta de outros números referenciados à fonte do Ministério da Educação, onde, entre outros aspetos, se mostrava que: (a) em 2012-2013 o número de alunos matriculados era de 63; em 2013-2014, de 305; em 2014-2015, de 199; e, em 2015-2016, de 564. Também aqui se denota uma tendência ascendente de alunos neste regime de ensino, com particular destaque para o último ano letivo recenseado; (b) Lisboa e Vale do Tejo sempre foi neste período, a região portuguesa onde se conseguiram identificar mais alunos matriculados em ensino doméstico, seguida a longa distância pela região Norte do país; (c) na peça jornalística, a representante do Movimento Educação Livre foi da opinião de que havia uma subrepresentação do número de alunos coligidos, não dando conta daquelas famílias que tinham decidido retirar os filhos da escola após o início do ano letivo.

Em ambos os levantamentos, os números apresentam outra magnitude, por comparação com os outros registos de uma década atrás. Há certamente fatores com um potencial heurístico mais significativo do que aqueles que subjazem à propalada crise da escola, hoje ainda "mais amplos e heterogéneos", para retomar o diagnóstico de Afonso (2005, p.146). Não sendo despicienda, até porque é intrínseca à própria ideia de escola, não se pode, porém, isolar a crise de outros condicionalismos inerentes à atual fase do capitalismo, em si mesmos mais problemáticos para as economias dos países, em geral; e para as pessoas e os seus projetos de vida, em particular.

No caso de Portugal, a assistência financeira externa assegurada pela troika (FMI, Banco Central Europeu e União Europeia), a pedido do governo, entre 2011-2015, implicou a assunção de um Memorando de Entendimento cujas medidas tiveram impacto ainda não totalmente mensurável na estrutura social portuguesa, mas redundaram no empobrecimento de amplos sectores da população e no enfraquecimento do investimento público em sectores-chave, tais como as políticas sociais e a educação. Não havendo estudos que comprovem a correlação aqui subentendida, estamos em crer que o aumento exponencial do número de famílias que optaram 


\section{pro.posıções}

por educar e ensinar em casa pode ancorar na degradação das condições de vida das pessoas, sobretudo das pertencentes à classe média, cujos rendimentos foram substancialmente reduzidos e entre as quais mais incidiu o desemprego. A isso se aduz o leque de medidas políticas para a escola pública tomadas pelo governo conservador-direita naquele período, refletidas no aumento de alunos por turma/classe, na junção de escolas de vários ciclos sob a forma de agrupamentos e mega-agrupamentos, no despedimento de professores, na atenção privilegiada num core curricular clássico (matemática, ciências, língua portuguesa), na introdução de exames nacionais estandardizados no final de cada ciclo de ensino, no acentuar dos mecanismos de avaliação externa com ênfase nos resultados escolares, na redução/eliminação das componentes curriculares não-letivas, na indução de pedagogias de natureza mais transmissiva, entre outras. Não será, pois, de estranhar que o efeito conjugado desta crise mais vasta na condição socioeconómica das famílias, com o encolbimento da escola e a sua tradução numa espécie de "campo de treinos" (Palhares, 2014), tenha induzido a procura de outras soluções educativas e letivas mais compatíveis com a sua identidade e práxis de vida.

Mas a expressão do ensino doméstico em Portugal na atualidade em muito se deve ao interesse despertado nos mass media e ao espaço que foi gradualmente conquistando na internet e correlativas redes sociais. Os últimos sete anos têm sido profícuos em atividades sociais em prol do ensino doméstico, tal como se observa na Figura 1. A criação de três blogues no ano 2007 foi, três anos mais tarde, acompanhada por atividade no Facebook e edição de notícias em jornais e revistas. Em 2013, o número de blogues em atividade tinha subido para treze, ao mesmo tempo em que se registavam sete grupos no Facebook e uma atenção crescente por parte dos canais de televisão. No ano 2014, consolidou-se a tendência de aumento da conetividade em rede no Facebook. Entre a atividade na internet e na televisão, salientamos as oito entrevistas realizadas por quatro estações de televisão portuguesas entre 2012 e 2014, com algum impacto mediático no cenário educativo português. Apresentando o ensino doméstico ao nível das suas virtudes e diferenças e por referência crítica à escola, entre 2012 e 2014, os 146 minutos de duração das peças televisivas foram objeto de mais de 9.500 visualizações após a sua disponibilização na internet. 


\section{pro.posıções \\ $e$-ISSN 1980-6248}

Figura 1 - Friso cronológico de eventos mediáticos do ensino doméstico

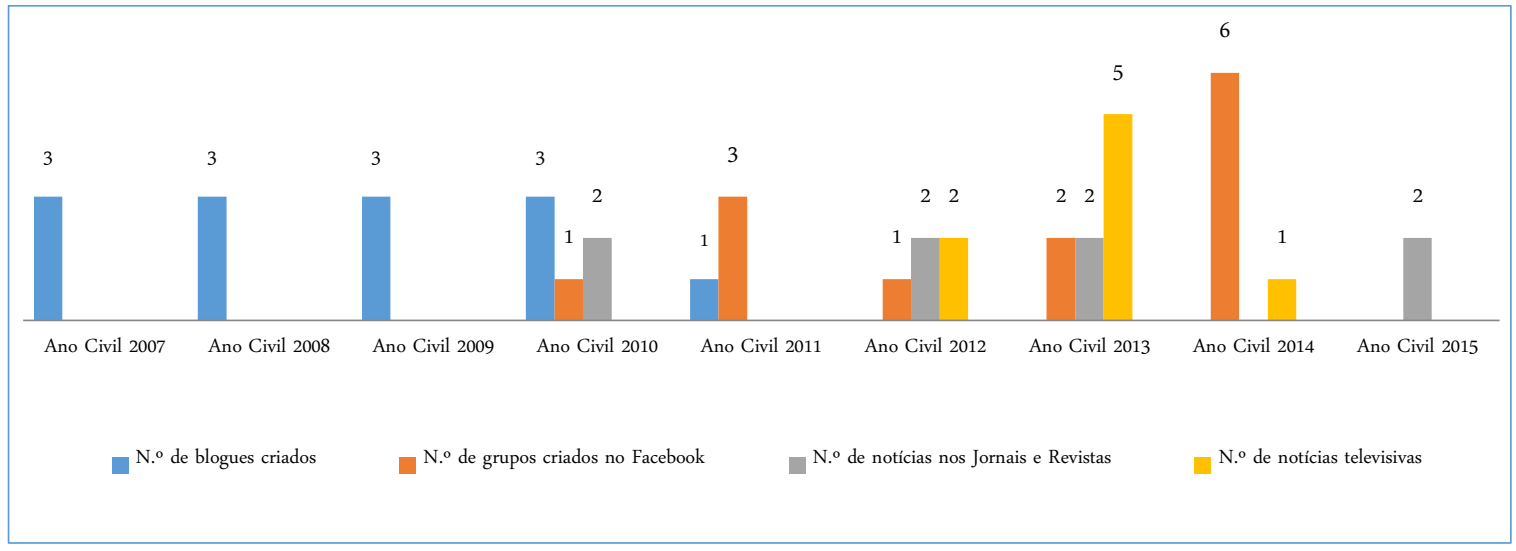

Fonte: Adaptado de Ribeiro (2015)

Como fenómeno socialmente construído, o ensino doméstico surgiu no espaço público português pela mão de operadores simbólico-ideológicos, sem qualquer filtragem crítica, como se de uma moda se tratasse e como se trouxesse novos argumentos de regeneração educativa da sociedade. Movidos pelo afã de querer informar, muitas vezes esses trabalhos jornalísticos abordam a realidade, usando "óculos particulares através dos quais veem certas coisas e não outras; e veem de uma certa maneira as coisas que veem" (Bourdieu, 2005, p. 12), correndo-se o risco de obnubilar da opinião pública os contornos da realidade e do seu sentido histórico. Nesses casos não é difícil admitir que a narrativa do ensino doméstico tenha granjeado simpatias diante da dramatização e do escrutínio permanentes da escola, sobretudo da escola pública.

No trabalho dinamizado pelas tecnologias de conetividade, o número de mensagens foi maior nos blogues do que no Facebook, não obstante se tenha vindo a assistir a uma redução da atividade bloguista e a um aumento das dinâmicas no Facebook. A comparação entre o Facebook e os blogues revelou que a percentagem de comentários às mensagens postadas no primeiro situava-se em 77\%, enquanto nos segundos era de 55\% (Ribeiro, 2015). Quer mais agora na rede social do Facebook, quer antes na blogosfera, estamos em crer que o crescimento recente do número de praticantes do ensino doméstico em Portugal em muito ficou a dever ao incremento da atividade das famílias no ciberespaço. Essa hipótese investigativa, a carecer de prova heurística, entende os indivíduos que formam essa atividade como grupos de interesse, exercendo uma pressão pública sistemática para alargar a sua base de praticantes e, por conseguinte, de apoio (Berger, 1989). Independentemente das razões que impeliram as famílias 


\section{pro.posıções}

$e$-ISSN 1980-6248

para a assunção da escolarização na esfera doméstica, seja por condicionantes socioeconómicas, seja por motivações ideológicas/religiosas ou outras, o que se constata é que se conjugam circunstâncias para que esse empreendimento educativo se desenvolva sob a supervisão mais direta de um dos membros do casal, ou da agremiação de interesses de agregados familiares em situações similares, como à frente veremos.

Um pequeno formulário que enviamos às famílias que identificamos com filhos em ensino doméstico $(\mathrm{n}=77)$, procurando conhecer a sua profissão principal, a situação na profissão, entre outras variáveis desta natureza, permitiu-nos identificar os grandes grupos principais de atividade e os indicadores socioprofissionais individuais e familiares de classe (Tabelas 2 e 4).

A observação da Tabela 2 revela-nos progenitores com atividades profissionais declaradas no grupo dos especialistas intelectuais e científicos, isto é, aquelas que têm por base elevados níveis de escolaridade. Sendo uma realidade mais constatada entre os pais (46,8\%), neste grupo encontramos muitos diretores(as) de empresas, professores(as) (de vários graus de ensino), artistas plásticos, engenheiros(as), entre outros. Aliado ao capital cultural, o ensino doméstico português parece fazer recair sobre as mães a tarefa de supervisão direta das crianças, deduzindo-se tal facto pelo elevado número de domésticas $(45,4 \%)$ - e dois domésticos ilustrado na Tabela 2.

Tabela 2 - Grupos de profissões a que pertencem o pai e a mãe

\begin{tabular}{|l|l|l|l|l|}
\hline & Pai & Mãe \\
\cline { 2 - 6 } & $\mathbf{F}_{\mathbf{i}}$ & \% & $\mathbf{F}_{\mathbf{i}}$ & $\mathbf{\%}$ \\
\hline $\begin{array}{l}\text { Quadros superiores da administração pública, } \\
\text { dirigentes e quadros superiores de empresas }\end{array}$ & 3 & 3.9 & 4 & 5.2 \\
\hline Especialistas das profissões intelectuais e científicas & 36 & 46.7 & 20 & 26.0 \\
\hline Técnicos e profissionais de nível intermédio & 8 & 10.4 & 7 & 9.1 \\
\hline Pessoal administrativo e similares & 6 & 7.8 & 4 & 5.2 \\
\hline Pessoal dos serviços e vendedores & 9 & 11.7 & 2 & 2.6 \\
\hline $\begin{array}{l}\text { Agricultores e trabalhadores qualificados da } \\
\text { agricultura e pescas }\end{array}$ & 2 & & & \\
\hline Operários, artífices e trabalhadores similares & 3 & 3.6 & - & -- \\
\hline Trabalhadores não qualificados & 1 & 1.3 & 2 & 2.3 \\
\hline Domésticas(os) & 2 & 2.6 & 35 & 45.4 \\
\hline Desconhecido(a) & 7 & 9.1 & 2 & 2.6 \\
\hline Total & 77 & 100.0 & 77 & 100.0 \\
\hline
\end{tabular}

Fonte: Adaptado de Ribeiro (2015) 


\section{pro.posıções}

$e$-ISSN 1980-6248

Tabela 3 - Responsáveis pela administração do ensino doméstico

\begin{tabular}{|l|l|l|}
\hline & Frequência & Percentagem \\
\hline Mãe & 48 & 64.0 \\
\hline Mãe, Outros & 2 & 2.7 \\
\hline Mãe, Pai & 10 & 13.3 \\
\hline Mãe, Pai, Avós, Outros & 1 & 1.4 \\
\hline Mãe, Pai, Outros & 3 & 4.0 \\
\hline Pai & 4 & 5.3 \\
\hline Outros & 6 & 8.0 \\
\hline NR & 1 & 1.3 \\
\hline Total & 75 & 100.0 \\
\hline
\end{tabular}

Fonte: Adaptado de Ribeiro (2015)

Não sendo uma categoria formal da atividade profissional, a inclusão das domésticas nesta categorização pretende sublinhar a importância, na educação e no ensino em casa, das progenitoras, que supostamente abdicam da sua inserção ou permanência no mercado de trabalho, tal como, aliás, já foi amplamente comprovado na literatura internacional sobre o homeschooling (Gaither, 2008; Kunzman, 2009; Mayberry et al., 1995; Stevens, 2001). Essa tendência já havia sido anteriormente identificada por nós quando da exploração deste fenómeno na sociedade portuguesa (Ribeiro, 2010), sendo agora confirmada no subsequente trabalho de campo (Ribeiro, 2015). Inquirindo as famílias sobre quem seria o principal responsável pela implementação do ensino doméstico, as respostas sublinharam a omnipresença da mãe, isoladamente $(64,0 \%)$ ou acompanhada (21,3\%), a presença residual do pai $(5,3 \%) \mathrm{e}$ a responsabilidade partilhada entre o casal em dez casos (Tabela 3). Há situações em que a mãe recorre ao auxílio de outros membros da família alargada, de tutores e/ou à contratação de professores.

Por sua vez, a Tabela 4 resulta do apuramento do indicador de classe das famílias estudadas, tendo por base a tipologia ACM proposta por Costa, Machado e Almeida (1990), Costa (1999) e Almeida, Machado e Costa (2006). Constata-se, assim, a prevalência de famílias situadas em estratos sociais detentores de mais recursos, tanto económicos como culturais, exercendo a sua atividade por conta própria (com e sem trabalhadores assalariados) ou desempenhando cargos de direção. É disto elucidativa a situação dos Empresários, Dirigentes e Profissionais Liberais (EDL), muito embora mais frequente quando ambos os progenitores exercem uma atividade laboral. Os Profissionais Técnicos e de Enquadramento (representando $53,2 \%$ das famílias inquiridas), são, sobretudo, indivíduos de escolarização superior, cuja 


\section{pro.posıções}

atividade assalariada tem implícito o desempenho de cargos e funções de elevado nível técnico, cultural e/ou artístico.

Tabela 4 - Indicador socioprofissional familiar de classe

\begin{tabular}{|l|l|l|}
\hline & Frequência & Percentagem \\
\hline $\begin{array}{l}\text { Empresários, Dirigentes e Profissionais Liberais } \\
\text { (EDL) }\end{array}$ & 18 & 23.4 \\
\hline Profissionais Técnicos e de Enquadramento (PTE) & 41 & 53.2 \\
\hline Trabalhadores Independentes Pluriactivos (TIpl) & 1 & 1.3 \\
\hline Empregados Executantes (EE) & 13 & 16.9 \\
\hline Operários (O) & 1 & 1.3 \\
\hline Assalariados Agrícolas (AA) & 1 & 1.3 \\
\hline Assalariados Executantes Pluriactivos (AEpl) & 2 & 2.6 \\
\hline Total & 77 & 100.0 \\
\hline
\end{tabular}

Fonte: Adaptado de Ribeiro (2015)

\section{Espaço social e disposições do ensino doméstico}

O conhecimento empírico que enquadra este texto filia-se a uma abordagem de natureza qualitativa de longa duração, tendo-se adotado o método de estudo de caso, variante multicasos (Bogdan \& Biklen, 1994; Stake, 2007) e mobilizado várias técnicas de pesquisa. As diversas diligências microetnográficas procuraram abarcar o enquadramento influenciador e gerador das significações, partilhado nas dinâmicas laborais domésticas e a partir delas. Saliente-se o facto de termos convivido, observado e entrevistado 24 famílias, realizado 5 focus groups e conseguido administrar 77 inquéritos por questionário. A amostra configurada por este inquérito é nãoprobabilística, tipo "bola de neve", não sendo, por isso, passível de deduzir, a partir dela, generalizações para o conjunto das famílias que praticam o ensino doméstico em Portugal. Foram ainda acionadas outras démarches de pesquisa, tais como aquelas que atrás mereceram um apontamento reflexivo e analítico, designadamente as que compilaram os dados sobre o uso das novas tecnologias da informação e comunicação e das redes sociais pelos homeschoolers (ver Figura 1).

Contudo, a focalização que orientará esta secção tomará como centrais os dados recolhidos pelo inquérito por questionário, que foram tratados e analisados com recurso ao software IBM SPSS Statistics (versão 23.0); e, de entre o output, destacamos as análises de correspondências múltiplas (ACM) realizadas. O recurso a esse procedimento pretendeu reduzir 


\section{pro.posıções \\ $e$-ISSN 1980-6248}

a quantidade da informação inerente a um conjunto de variáveis significativas na discriminação do espaço social do ensino doméstico. A Figura 2 procura dar conta das "principais dimensões estruturantes" desse espaço, e se ensaia a definição de "grupos com perfis (tendencialmente) homogéneos" (Carvalho, 2008, p.31), tendo para o efeito complementado aquele procedimento com recurso a uma análise de clusters (método k-means).

Após a execução do procedimento ACM com o máximo de soluções possíveis (28), atendendo à especificidade das variáveis envolvidas, decidimos reter três dimensões por razões teóricas, muito embora, do ponto de vista técnico, quer a inércia quer as medidas de discriminação tivessem apontado idealmente para a seleção de apenas duas dimensões. A percentagem de variância explicada apurada para as três dimensões foi, respetivamente, 20,47 $\%, 12,94 \%$ e $9,95 \%$. Optamos por projetar os 3 clusters no plano $1 * 2$ da ACM, dado que este apresenta uma maior segmentação e riqueza na leitura dos perfis das famílias que responderam ao inquérito por questionário.

A Figura 2 cruza as duas dimensões mais significativas, dando sentido ilustrativo a um possível espaço homeschooler português, estruturado em torno do que denominamos "Pedagogias e contextos educativos em confessionalidade" (eixo 1) e "Condições económicas e culturais" (eixo 2). Ou seja, se, em relação ao contributo do primeiro eixo para a construção desse espaço, vamos encontrar, como variáveis que mais discriminam: o tipo de educador (tradicional, eclético e unschooler); a denominação religiosa de pertença (adventista do $7 .^{\circ}$ dia, católica, outras denominações e sem religião); e o espaço onde se realiza o ensino doméstico (centro de apoio e/ou casa), por sua vez, o rendimento ilíquido do agregado familiar (até 7 mil euros, entre 7 e 20 mil euros, entre 20 e 40 mil euros e entre 40 e 80 mil euros), o nível de escolaridade da mãe e do pai (até ensino secundário, bacharelato/licenciatura e pós-graduação), o estado civil (solteiro/divorciado/viúvo e casado) e a responsabilidade pelo ensino doméstico (só a mãe e mãe e outros) constituem as variáveis que mais contribuem para a variabilidade observada em torno do eixo 2. 


\section{pro.posıções}

Figura 2-Disposições dos clusters do ensino doméstico em Portugal

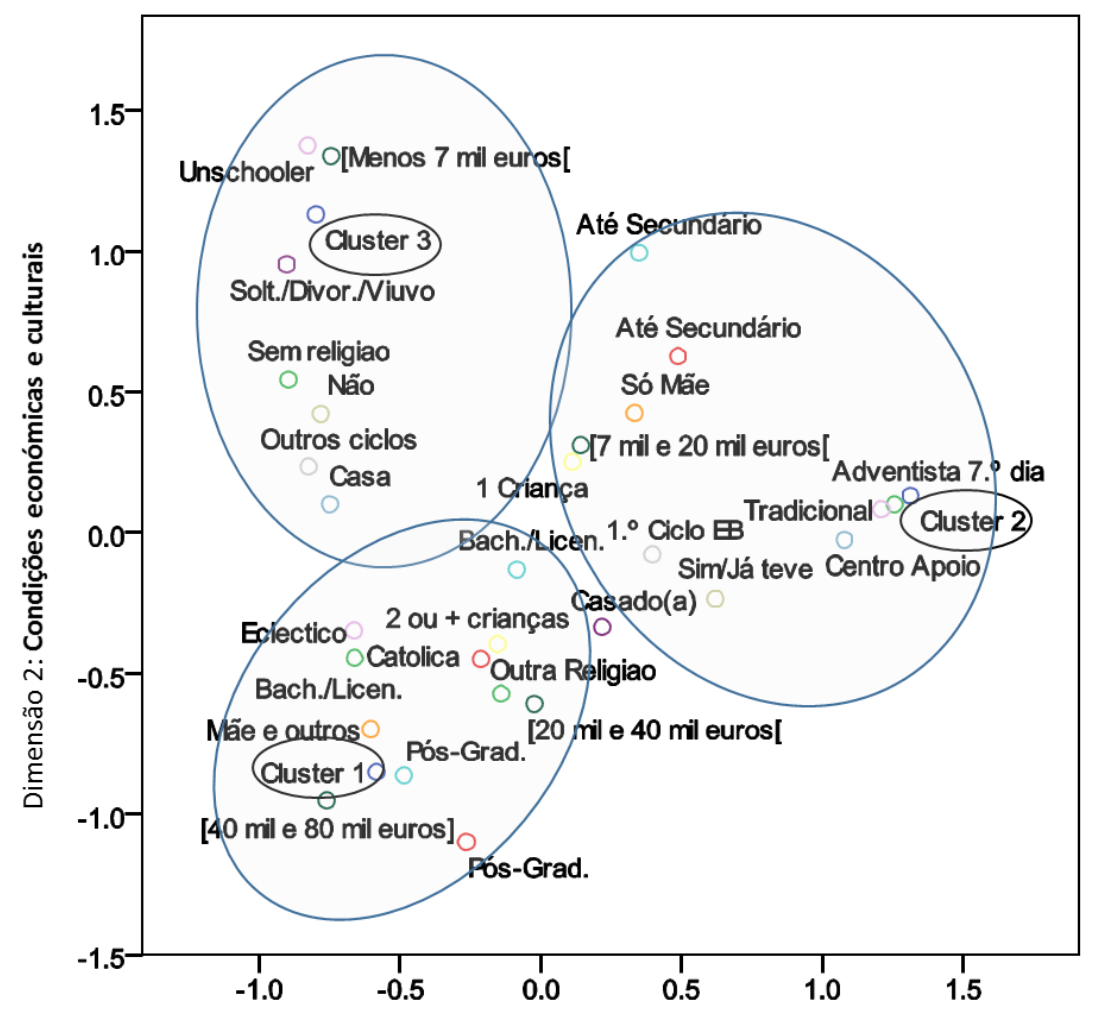

Clusters Ensino Doméstico

em Portugal

denominação religiosa

Ensino Doméstico com

outras famlias

Estado Civil

N. ${ }^{\circ}$ crianças em $\mathrm{ED}$

Nível de ensino cônjuge

Níel de ensino mãe

Nível de escolaridadade do

aluno

Onde é que faz Ensino

Doméstico

Rendimento ilíquido anual do

agregado familiar

Responsável pelo $\mathbb{D}$

Tipo de educador

Dimensão 1: Pedagogias e contextos educativos em confessionalidade

Fonte: Inquérito por questionário administrado às famílias praticantes de ensino doméstico em Portugal (Adaptado de Ribeiro, 2015)

O espaço do ensino doméstico português aparece, assim, marcado por orientações religiosas distintas - na oposição, aliás, encontramos famílias sem quaisquer crenças declaradas -, a que se associam o modo como se ensina e o contexto em que se realiza. Não deixa de ser intrigante que a retirada, ou a não inscrição, das crianças da/na escola nem sempre pressuponha que as famílias optem por as ensinar na esfera doméstica.

Como observamos anteriormente (Ribeiro, 2010, 2015), emergiram alternativas educacionais resultantes da junção de várias crianças em "centros de apoio". São esquemas organizacionais híbridos, que conjugam elementos formais escolares com os padrões de ensino maternal. Para além do espaço familiar, a presença de centros de aprendizagem voluntária, em forma de rede ou outras configurações, possibilita ambientes de aprendizagem recíproca onde 


\section{pro.posições}

10.1590/1980-6248-2016-0098

$e$-ISSN 1980-6248

as crianças de várias idades podem aprender umas com as outras. Unidas pelas convicções familiares em contextos espaçotemporais similares às classes/turmas das escolas, mas que, em essência, contradizem uma conceção mais formal de ensino doméstico, o aludido espaço é igualmente segmentado do ponto de vista socioeconómico; e importa relevar as diferenças que se cavam pela posse ou pela ausência de recursos materiais e culturais. Gaither (2008) diz que isso tem algo de perplexo, pois "os casos de maior sucesso e desenvolvimento começam a parecer-se com escolas por vezes contratando especialistas para ensinarem assuntos com elevado grau de dificuldade, como sejam o cálculo, línguas estrangeiras, ou física” (p. 211). Será isso um entreposto organizacional (Torres, 2004) entre o homeschooling e a Escola?

A complementaridade propiciada pela análise de clusters permite, entretanto, sintetizar o espaço social do ensino doméstico com as seguintes disposições:

Cluster $1(38,7 \%)$ - famílias com os mais altos rendimentos entre os inquiridos, com níveis de escolaridade superior e pós-graduada, tendencialmente católicos e/ou professando outros credos de natureza cristã. Mais de $80 \%$ eram casados, e uma parte significativa das famílias tinha optado por residir no espaço rural (42\%). A responsabilidade pelo ensino doméstico era dividida entre a mãe e outros intervenientes, fossem o pai ou outros familiares ou então tutores e/ou professores contratados. Era frequente encontrar mais de uma criança dessas famílias em escolaridade doméstica, um processo que, por vezes, já tinha sido partilhado, ou estava em partilha, com outras famílias (52\%). Porém, o espaço de ensino de eleição indicado era o lar, com a adoção de práticas educativas/pedagógicas de tipo eclético, isto é, uma combinatória de métodos tradicionais de ensino com práticas unschooling.

Cluster $2(34,7 \%)$ - famílias vivendo em cidades e/ou em subúrbios auferiam rendimentos entre os 7 e os 20 mil euros anuais (nalguns casos entre 20 e 40 mil euros) e, na altura da administração do inquérito, todos eram casados. Quase todas estas famílias declararam pertencer à religião adventista do $7 .^{\circ}$ dia $(89$ \%). Do ponto de vista da escolaridade, enquanto a maioria das mães era detentora de um curso superior, a maioria dos pais não ia além do ensino secundário/médio. Porventura associados, há traços característicos do ensino doméstico nestas famílias: designadamente estarem partilhando ou já terem partilhado esta prática de escolarização com outras famílias, ser só a mãe indicada como responsável e recorrerem a centros de apoio $\left(96 \%\right.$ ). Envolvendo quase sempre apenas uma criança - e do $10^{\circ}$ ciclo de escolaridade -, releve-se, ainda, o facto de estas famílias privilegiarem um tipo de pedagogia 


\section{pro.posıções}

10.1590/1980-6248-2016-0098

$e$-ISSN 1980-6248

tradicional, recorrendo normalmente a currículos já existentes, livros didáticos, livros e/ou palestras.

Cluster $3(26,7 \%)$ - isolamos neste agrupamento 20 famílias, caracterizadas por baixos rendimentos anuais, apenas um terço no estado civil casado, a mãe com níveis de escolaridade entre o secundário e o superior, enquanto o pai apenas detém o ensino secundário; vivem sobretudo nas cidades ou nas redondezas, e 12 famílias declararam-se sem religião. A generalidade nunca praticou o ensino doméstico com outras famílias, fazendo-o privilegiadamente em casa (18 famílias), envolvendo apenas uma criança, muito embora essa frequente outros níveis de escolaridade para além do $1 .^{\circ}$ ciclo. Em 15 famílias, a mãe assume-se como a única responsável. Em 9 educadores com perfil unschooler, 8 integram-se neste cluster, sendo-lhes inerente na sua ação pedagógica deixar fluir as aprendizagens das crianças de acordo com a iniciativa delas e balizadas pelo seu próprio interesse e ritmo de crescimento.

A observação desse fenómeno em projetos futuros permitirá aferir algumas destas segmentações e adensar o olhar sociológico em alguns insights captados por entre os dados do inquérito por questionário. A explosão estatística do número de famílias recenseadas nos últimos anos letivos irá pôr à prova algumas das evidências cristalizadas no espaço mediático e mesmo em alguns trabalhos de pesquisa. Houve, entretanto, algumas tendências anteriormente observadas na pesquisa de terreno, que se tornaram ainda mais claras. Por exemplo, de acordo com os dados do inquérito, $75 \%$ das famílias que praticam ensino doméstico caracterizam-se pela residência comum e pela cooperação entre adultos de dois sexos e os filhos que eles geraram (não conhecemos casos de adoção de crianças). E são um pouco alheios ao cenário crescente de divórcios constatado na sociedade portuguesa (Gaspar, Ramos, \& Ferreira, 2013). Trata-se de uma população em busca de mobilidade social, que não desdenha a obtenção de maiores índices de qualificação pessoal, técnico e comercial. E, nesse sentido, uma das suas grandes bandeiras traduz-se numa educação parental que considera os primeiros anos de vida cruciais para a educação e o desenvolvimento da criança. Como vimos, as mães assumem um papel crucial neste processo, frequentemente ancorado nos seus níveis superiores de escolarização, e não raras vezes levando-as a interromper a sua atividade profissional para se dedicarem à prática diária do ensino doméstico em Portugal. Mães que, na linha de uma "maternalização intensiva" (Hays, 1996), negam, interrompem ou reconstroem o seu próprio projeto segundo os interessesnecessidades do educando. 


\section{pro.posições}

$e$-ISSN 1980-6248

Há, contudo, nuances nas justificações e nas crenças subjacentes às predisposições e às práticas das famílias envolvidas no ensino doméstico, divergindo, por exemplo, nos papéis desempenhados pelos adultos no processo educacional e no lugar aqui ocupado pelos educandos. As aprendizagens quotidianas propiciadas pela experiência e pela descoberta, tendo como ponto de partida os interesses e a curiosidade natural das crianças, sendo estas que decidem o que aprender, como aprender e quando aprender, configuram um mundo de conhecimentos situado nos antípodas da atual forma escolar e devolvem ao sujeito a responsabilidade de se construir autonomamente nos diversos contextos e na comunidade de referência. Porém, nem todas as crianças gozam dessa informalidade educativa. Algumas famílias ensinam os seus filhos, decalcando os traços da cultura escolar, fixando horários e períodos escolares e adotando um currículo baseado no currículo oficial da escola (Ribeiro, 2010). Essa orientação revela cautelas e sentido estratégico, na medida em que, por um lado, há a necessidade de se prestarem provas/exames no final de cada ciclo de ensino e, por outro lado, a retirada das crianças da escola nem sempre elimina a probabilidade de elas lá regressarem. Da mesma forma que há famílias que, ao longo do tempo, se vão libertando mais do cânone escolar, privilegiando a informalidade e a autonomia cognitiva do educando, também há casos de outras famílias que se deslocam no sentido oposto (Ribeiro, 2010, 2015).

\section{As perspetivas de aprendizagem que o ensino doméstico encerra}

A relação entre a responsabilização individual e familiar e a aprendizagem desloca o centro da instrução centrada no professor para uma aproximação centrada no aprendente. E, dado que o ensino doméstico é uma forma educativa que celebra o centrossistema no educando, com variações lógicas segundo a narrativa de base, é por nós assente que as famílias põem em ação uma combinatória de possibilidades de aprendizagem mais ou menos dependentes das suas inscrições axiológico-normativas.

A aprendizagem pode acontecer em função dos propósitos mais ou menos formais da tarefa em que estão inseridos. Se, no sentido radical unschooling, a aprendizagem é de forma assistemática e não diretamente marcada pela intencionalidade, muito embora contextualizada no quotidiano e na experiência, isso invalida que essa aprendizagem decorra da influência de outros agentes que providenciam formalmente estímulos que despertam a atenção do educando. 


\section{pro.posıções

Adaptando o pensamento de Rogers (2014) à abordagem sobre o ensino doméstico, “às vezes, os alunos pretendem aprender, outras vezes eles não têm intenção. Às vezes, a agência pretende que os alunos aprendam, outras vezes não, mas na verdade promovem a aprendizagem de forma não intencional” (p. 4), isso significa que a aprendizagem faz-se segundo intensidades diferentes de formalidade e informalidade. Rogers (2014) captou bem essa ideia, quando escreveu que "a aprendizagem informal e formal pode ser vista num contínuo desde a aprendizagem acidental/incidental através da aprendizagem consciente, autoaprendizagem, para aprendizagem não-formal e formal” (p. 5).

$\mathrm{Na}$ generalidade, as famílias sabem da importância que a aprendizagem informal tem na formação do caráter dos seus filhos e no desenvolvimento da sua personalidade. Tendo presentes os motivos aduzidos pelas famílias para a retirada dos seus filhos da escola, foi inequívoca a justificação de que em casa os educandos desenvolvem carateres e personalidades mais de acordo com as suas finalidades religiosas, emocionais e educativo-pedagógicas. Essa argumentação pretende demonstrar que, com Sedlmayr (2014), estão conscientes de que a configuração do espírito e do caráter dos seus filhos depende das inumeráveis pequenas ações insensíveis que se produzem em cada instante e às quais não damos atenção por causa da sua insignificância aparente. Por isso mesmo, a escola surge como consequência e perpetuação das disfunções sociais, não questionadas, transmitidas de geração em geração; e o ensino doméstico, como a forma de educação que permite que os educandos desenvolvam as suas respostas para as suas próprias questões, visões interiores e valores (Sedlmayr, 2014).

A partir da Tabela 5, independentemente de quem está no centrossistema, as famílias entendem a aprendizagem como transformação da existência atual para uma outra mais includente, aberta, emocionalmente capaz de mudar, reflexiva, de modo a gerar crenças e opiniões mais amplas e profundas. Isto significa que o educando tem a sua própria literacia. Literacia decorrente das dinâmicas humanas familiares e comunitárias, que é potenciada pela construção de um imaginário social construído através dos contos, das histórias, da vivência de acontecimentos de forma referente aos seus pressupostos de base. Essa referência, em torno da aprendizagem que fazem da cultura que os envolve, constrói a sua autorreferência. Uma autorreferência construída através das aprendizagens fazedoras de sentido na ação quotidiana com a sua família e comunidade próxima. 


\section{pro.posıções}

$e$-ISSN 1980-6248

Tabela 5 - Perspetivas de aprendizagem e atributos dominantes nas famílias que praticam ensino doméstico em Portugal

\begin{tabular}{|c|c|c|c|}
\hline Características & Famílias Saber tornar-se & Famílias Saber estar com & Famílias Saber ser \\
\hline Finalidade & $\begin{array}{l}\text { Construção orientada de } \\
\text { atitudes, valores, } \\
\text { competências e conceitos }\end{array}$ & $\begin{array}{l}\text { Construção interativa de } \\
\text { atitudes, valores, } \\
\text { competências e conceitos }\end{array}$ & $\begin{array}{l}\text { Autoconstrução de } \\
\text { atitudes, valores, } \\
\text { competências e } \\
\text { conceitos }\end{array}$ \\
\hline $\begin{array}{l}\text { Vertente } \\
\text { epistemológica }\end{array}$ & $\begin{array}{l}\text { Conhecimento crítico } \\
\text { segundo a } \\
\text { monorracionalidade }\end{array}$ & Pluralismo metodológico & $\begin{array}{l}\text { Natureza espontânea do } \\
\text { conhecimento }\end{array}$ \\
\hline $\begin{array}{l}\text { Vertente da } \\
\text { aprendizagem }\end{array}$ & $\begin{array}{l}\text { Poder refletir e decidir } \\
\text { em prol de }\end{array}$ & Conhecer para conviver & $\begin{array}{l}\text { Conhecer a partir da } \\
\text { intuição }\end{array}$ \\
\hline $\begin{array}{l}\text { Papel do } \\
\text { educador }\end{array}$ & Educação da vontade & Aprendizagem emocional & $\begin{array}{l}\text { Assume um papel } \\
\text { discreto, observador a } \\
\text { distância e ator, quando } \\
\text { urgente ou solicitado }\end{array}$ \\
\hline $\begin{array}{l}\text { Papel do } \\
\text { educando }\end{array}$ & $\begin{array}{l}\text { Aprender a narrativa de } \\
\text { base }\end{array}$ & $\begin{array}{l}\text { Educando como } \\
\text { construtor da sua } \\
\text { aprendizagem concetual }\end{array}$ & $\begin{array}{l}\text { Educando ativo, } \\
\text { assumindo um papel de } \\
\text { autopesquisa e } \\
\text { autodescoberta do } \\
\text { conhecimento }\end{array}$ \\
\hline $\begin{array}{l}\text { Caracterização } \\
\text { didático- } \\
\text { pedagógica }\end{array}$ & $\begin{array}{l}\text { Sequencialidade na } \\
\text { referenciação à norma }\end{array}$ & $\begin{array}{l}\text { Sequencialidade no } \\
\text { percurso da mudança }\end{array}$ & Unschooling \\
\hline
\end{tabular}

Fonte: Adaptado de Ribeiro (2015)

As famílias dizem que os alunos aprendem o conhecimento tradicional, valores e práticas e, ao mesmo tempo, cotejam novos valores e práticas. O conhecer refere-se, implícita e explicitamente, à ideia de encontro; à capacidade de identificação, de reconhecer; à relação com o conhecimento, o saber; a saber poder agir; a poder ser capaz de vivenciar uma situação; a poder apropriar-se de informações, de enunciados, de fragmentos do conhecimento, segundo a sua interpretação e à luz do conhecimento que as famílias saber tornar-se detêm da sua narrativa de base, da sua monorracionalidade. No sentido das famílias saber ser, dada a plurirracionalidade de narrativas, será conhecimento o que se constituir em disposições para as expetativas dos educandos, da sua estabilidade holística. Há, portanto, habitus cujas naturezas são o que forem o sentido da narrativa.

Se, no sentido saber tornar-se, os fragmentos, os sensos de normalidade, os padrões comportamentais e as regras de vida são mais contextualizáveis, intencionais, sequenciais e sistemáticos e a aprendizagem é mais formalmente situada, no sentido saber ser, o facto de o 


\section{pro.posições}

babitus ser naturalizado de forma não consciente e não intencional não significa que os educandos não aprendam um conjunto de valores, que não sejam socializados numa determinada cultura que lhes serve de contexto e de significação.

Seja num sentido formal ou informal, é, no entanto, esse último que determina o que e como se aprendem, conscienciosamente, os valores, as assunções, as expetativas, as aspirações e as motivações que se atribuem a todas as situações de aprendizagem (Rogers, 2014). Graduadamente diferenciada e diversificada, a aprendizagem informal ocorre através da vivência contínua e permanente no universo dos contextos familiares e em outros mais extensivos. É a partir desse conhecimento que os educandos reinterpretam os papéis antigos, as conceções narradas e as posições ditadas. É uma aprendizagem ordinária em função das mudanças do meio. Mais no sentido saber tornar-se, a aprendizagem informal ocorre através de processos assimilativos que são construídos para o educando com intencionalidade familiar. A vivência da Igreja, das configurações intencionais presentes, dos processos de gestão da cultura eclesiástica, tudo isso é feito com o objetivo de que a vontade do educando seja a de se conformar com a estrutura de conhecimento existente. Comum aos dois sentidos é que a aprendizagem informal ocorre segundo o modo de operacionalização dos contextos de interação entre as pessoas.

As famílias saber tornar-se seguem um padrão de aprendizagem por transmissão, com aproximações à aprendizagem por pesquisa no papel do educador e na caracterização didáticopedagógica. A natureza da aprendizagem das famílias estar com é de mudança concetual, com aproximações à aprendizagem por pesquisa e à aprendizagem por descoberta. As famílias saber ser seguem uma natureza da aprendizagem mista - entre a aprendizagem por descoberta e a aprendizagem por pesquisa -, com duas aproximações à aprendizagem por mudança concetual.

As aproximações que as famílias saber tornar-se fazem têm a ver com a problematização de saberes e com a construção de reflexões críticas. As aproximações das famílias saber estar com à aprendizagem por pesquisa têm a ver, sobretudo, com o estudo de problemas abertos e com a valorização da interdisciplinaridade. As aproximações que as famílias saber ser fazem à aprendizagem por mudança concetual têm a ver com a conceção do educando como construtor da sua aprendizagem e com o facto de o conhecimento ser encarado como sendo um percurso descontínuo e incerto, dinâmico, dialético e pouco estruturado. Regista-se que essas famílias consideram a questão didática e pedagógica de uma forma referida de autodidática e pedagogicamente não diretiva. 


\section{pro.posições}

$e$-ISSN 1980-6248

O unschooling como matriz educacional faz emergir o nó górdio da pedagogia, isto é, a não existência desta de uma forma diretiva, intencional e sistemática, mas porventura implícita e omnipresente no quotidiano, coloca sempre em questão a autonomia do educando. De que será o educando autónomo? Da escola não o será absolutamente, porque terá de se subordinar aos exames nacionais, com tudo o que isso implica em nível de aprendizagem dos conteúdos. Sê-lo-á da sua família?

No limite, estaremos em presença de uma gradação relativa da possibilidade de a educação ser desenvolvida por meio de formas e processos à escolha das famílias, mas tendo sempre como fundo o facto de as crianças e os adolescentes serem alunos matriculados numa escola e integrarem as estatísticas oficiais da escolarização, não se furtando ao dever de prestar provas de conhecimentos. Por isso, o unschooling não será mais do que um idealismo crítico kantiano que se desenvolve por contraponto à escola como instituição.

Entre a escola e o ensino doméstico emerge uma diferenciação teleológica: se a primeira é comandada pelo determinismo causal, agora bytificado e teleonómico segundo a causalidade linear, no ensino doméstico há uma preocupação no sentido pós-linear, isto é, no sentido saber ser diminui-se o tipo de causalidade circular (causa-efeito-causa) e aumenta-se a indiferenciação causa-fim. Se, na escola, a capacidade preditiva ultrapassa largamente as nossas capacidades de observação natural, no ensino doméstico a capacidade preditiva das famílias limita-se a fenómenos da vida corrente. $\mathrm{Na}$ escola recorre-se predominantemente a modos operativos de transformação do real, com recursos a ações estereotipadas, ignorando voluntariamente muitos traços da situação estudada. No ensino doméstico, mais no sentido saber ser, predomina o modo figurativo sobre o operativo e privilegiam-se experiências sensoriais e cinestésicas que tendem a reproduzir a realidade com base em aspetos óbvios da perceção.

Contrariamente à escola, no ensino doméstico o modo de organização educativo é pensado, conscientemente ou não, em função do educando, a partir de uma narrativa que lhe é própria. E porque estamos a lidar com educandos que viverão em contextos sociais plurais e frequentemente contraditórios, algo dissonantes com o património de disposições, hábitos e capacidades adquirido na mundividência de base familiar e das interconexões do espaço doméstico, prefigura-se como um desafio investigativo em longo prazo estudar na diacronia o impacto e os resultados desse otimismo reformador parentocrático cuja força motriz se ancorou 


\section{pro.posıções}

na desconfiança em relação à escola como a instituição-chave na construção da cidade e dos sujeitos que a habitam.

\section{Notas finais}

A partir deste olhar que consideramos crítico sobre o ensino doméstico como um fenómeno educativo, da abordagem voltada para as suas dimensões não-formais e informais, há considerações a fazer para a compreensão da instituição escola a partir deste lado de fora, que é, conforme vimos, por vezes híbrido e mimético no que à forma escolar diz respeito.

Ora, diante da escola, o ensino doméstico é contrário aos horizontes formativos da criança segundo o interesse de toda a sociedade. Afastando-se as familias da escravidão laboral unlimitated e a escola desassumindo a responsabilidade de instaurar a civilização dos costumes nestes educandos e de um ideal de adulto civilizado, em contraponto à condição natural da criança, o ensino doméstico é incógnito ou nada nos diz sobre a potenciação da emancipação de indivíduos.

Levando em conta que as famílias veiculam processos tanto mais autónomos quanto mais fundados na coletividade e na razão entre o cristianismo conservador e o progressismolibertário, que tipo de harmonização de talentos e posições e que forma de conjugação é que as famílias propõem para o postulado escolar moderno, em que a subjetividade dos indivíduos e a objetividade das funções sociais são percebidas como duas faces da mesma realidade?

Usando o pensamento de Derouet (2002), o progresso do conhecimento dessas famílias corresponde a uma difusão do pensamento crítico na sociedade. Mas, com Perrenoud (2002), se cada comunidade religiosa, étnica ou linguística, se cada classe social ou subgrupo da sociedade edificassem a sua forma de ensino, as escolas seriam mobilizadas em guerras de religião, conflitos étnicos, linguísticos, confrontos entre classes sociais, contribuindo "para a divisão da sociedade e não para a sua unidade" (p. 13).

As diferenças organizacionais entre as várias racionalidades que subjazem aos sujeitos investigados e à escola convencional são muito consistentes. $\mathrm{O}$ ensino doméstico diferencia-se na pluriformidade curricular; na flexibilidade de horário e de programação; nas metodologias dirigidas para o ensino individual, ou no máximo em pequenos grupos; na pluralidade de estilos 


\section{pro.posıções \\ $e$-ISSN 1980-6248}

de aprendizagem; no ensino ao ritmo do aluno; no controlo centrípeto; na maternização do ensino; na configuração variável e adaptável dos espaços; na diversidade elevada de meios; e nos recursos de aprendizagem e avaliação diária. Presta-se muita atenção às idiossincrasias dos alunos, ao constante nutrimento do desenvolvimento físico, cognitivo e espiritual e à constante elevação das necessidades da criança acima das demais prioridades da vida. Por isso, o ensino doméstico questiona a escola sobre o modo de funcionamento do modelo de organização convencional.

Entre o ambiente e a escola, nas famílias coexistem a ação desinteressada, o refúgio doméstico, a transversalidade e o investimento situacional. As relações plurais resultantes entre o ambiente e a escola devem instigar futuras investigações sobre a relação entre o controlo e a mútua limitação do poder entre si. 


\section{pro.posições \\ $e$-ISSN 1980-6248}

\section{Referências}

Afonso, A. J. (2005). A sociologia da educação em Portugal. Elementos para a configuração do “estado da arte”. In A. Teodoro, \& C. A. Torres (Orgs.), Educação crítica e utopia. Perspectivas para o século XXI (pp.129-158). Porto: Afrontamento.

Almeida, J. F., Machado, F., \& Costa, A. F. (2006). Social classes and values in Europe. Portuguese Journal of Social Science, 5(2), 95-117.

Appelbaum, R. P., \& Chambliss, J. C. (1995). Sociology. New York: Harper Collins.

Bendell, J. (1994). Parents who choose to educate their children at home. In J. M. Halstead (Ed.), Parental choice and education. Principles, policy and practice (pp. 151-163). London: Kogan Page.

Berger, S. D. (1989). La organización de los grupos de interés en Europa occidental. Madrid: Ministério de Trabajo.

Bertrand, Y., \& Valois, P. (1994). Paradigmas educacionais. Escola e sociedade. Lisboa: Instituto Piaget.

Bogdan, R., \& Biklen, S. (1994). Investigação qualitativa em educação. Uma introdução à teoria e aos métodos. Porto: Porto Editora.

Bourdieu, P. (1998). Meditações pascalianas. Oeiras: Celta.

Bourdieu, P. (2005). Sobre a televisão. Oeiras: Celta.

Carvalho, H. (2008). Análise multivariada de dados qualitativos. Utilização da análise de correspondências múltiplas com o SPSS. Lisboa: Sílabo.

Collom, E., \& Mitchell, D. E. (2005). Home schooling as a social movement: identifying the determinants of homeschoolers perceptions. Sociological Spectrum, 25. Recuperado em 21 de maio de 2012, de http://www.usm.maine.edu/soc/collom/collom\%26mitchell.pdf.

Costa, A. F. (1999). Sociedade de bairro. Dinâmicas sociais da identidade cultural. Oeiras: Celta.

Costa, A. F., Machado, F., \& Almeida, J. F. (1990). Estudantes e amigos: trajetórias de classe e redes de sociabilidade. Análise Social, XXV (105-106), 193-221. 


\section{pro.posições \\ $e$-ISSN 1980-6248}

10.1590/1980-6248-2016-0098

Derouet, J.-L. (2002). A sociologia das desigualdades de educação posta à prova pela segunda explosão escolar: Deslocamento dos questionamentos e reinício da crítica. Revista Brasileira de Educação, 21, 5-16.

Dubet, F. (2002). Le déclin de l'instituition. Paris: Seuil.

Fernandes, A. T. (1993). Religiosidade difusa e identidade confessional. Sociologia. Revista da Faculdade de Letras da Universidade do Porto, VIII, 7-135.

Gaither, M. (2008). Homeschool: An American history. New York: Palgrave Macmillan.

Gaspar, S., Ramos, M., \& Ferreira, A. (2013). Análise comparativa dos divórcios em casais nacionais. Sociologia. Revista da Faculdade de Letras da Universidade do Porto, XXVI, 81-111.

Gatto, J. T. (2005). Dumbing us down. The bidden curriculum of compulsory schooling. Gabriola Island, CA: New Society Publishers.

Gatto, J. T. (2010). Weapons of mass instruction. A schoolteacher's journey through the dark world of compulsory schooling. Gabriola Island, CA: New Society Publishers.

Gonçalves, M., Barra, L., \& Rosa, S. (2016, março 13). Viver e aprender sem ir à escola. Expresso. Retirado de http://expresso.sapo.pt/sociedade/2016-03-13-Viver-e-aprender-sem-ir-aescola.

Habermas, J. (1992). Legitimation crisis. Cambridge: Polity Press.

Hays, Sh. (1996). The cultural contradictions of motherhood. New Haven, CT: Yale University Press.

Kanter, R. M. (1972). Commitment and community: communes and utopias in sociological perspective. Cambridge, MA: Harvard University Press.

Kennedy, E. (2008). Homeschooling as reflexive modernity. Recuperado em 25 de junho de 2013, de http://repository.lib.ncsu.edu/ir/bitstream/1840.16/1355/1/etd.pdf.

Kunzman, R. (2009). Write these laws on your children. Inside the world of conservative christian homeschooling. Boston: Beacon Press.

Lahire, B. (2003). Crenças coletivas e desigualdades culturais. Educação \& Sociedade, 24 (84), 983995. 


\section{pro.posıções \\ $e$-ISSN 1980-6248}

10.1590/1980-6248-2016-0098

Lahire, B. (2005). Patrimónios individuais de disposições. Para uma sociologia à escala individual. Sociologia, Problemas e Práticas, 49, 11-42.

Luhmann, N. (1995). Individuo, individualidad, individualismo. Zona Abierta, 70/71, 53-157.

Mayberry, M., Knowles, G., Ray, B., \& Marlow, St. (1995). Home schooling. Parents as educators. Thousand Oaks, CA: Corwin Press, Inc.

Mellucci, A. (1996). Challenging codes. Collective action in the information age. Cambridge: University Press of Cambridge.

Palhares, J. A. (2014). A excelência académica na escola pública. Quotidianos escolares e não escolares de jovens enquanto alunos. In L. L. Torres, \& J. A. Palhares (Orgs.), Entre mais e melhor escola em democracia. Inclusão e excelência no sistema educativo português (pp. 5-26). Lisboa: Mundos Sociais

Perrenoud, Ph. (2002). Aprender a negociar a mudança em educação. Porto: ASA.

Ribeiro, A. (2010). O ensino doméstico e a organização escolar: um contributo sociológico-organizacional sobre a realidade portuguesa. Dissertação de Mestrado, Universidade do Minho, Braga, Portugal.

Ribeiro, A. (2015), O ensino doméstico em Portugal: uma abordagem sobre novas epistemologias organizacionais da educação, das subjetividades e dos quotidianos familiares. Tese de Doutoramento, Universidade do Minho, Braga, Portugal.

Rogers, A. (2014). The classroom and the everyday: The importance of informal learning for formal learning. Investigar em Educação, II ${ }^{\mathrm{a}}$ Série, 1, 7-34.

Santos, B. S. (1994). Pela mão de Alice. O social e o político na pós-modernidade. Porto: Afrontamento.

Sedlmayr, A. (2014). Livre para crescer. Sustentabilidade emocional, parentalidade com apego e unschooling. Smashwords, Inc. Recuperado em 30 de setembro de 2014, de https://www.smashwords.com/books/view/481175

Stake, R. E. (2007). A arte da investigação com estudos de caso. Lisboa: Fundação Calouste Gulbenkian.

Stevens, M. (2001). Kingdom of children. Culture and controversy in the homeschooling movement. Princeton \& Oxford: Princeton University Press. 


\section{pro.posıções \\ $e$-ISSN 1980-6248}

Torres, C. A. (2003). Democracia, educação e multiculturalismo: Dilemas da cidadania em um mundo globalizado. In C. A. Torres (Org.), Teoria crítica e sociologia política da educação (pp. 63-102). São Paulo: Cortez; Instituto Paulo Freire.

Torres, L. L. (2004). Cultura organizacional em contexto educativo. Sedimentos culturais e processos de construção do simbólico numa escola secundária. Braga: Universidade do Minho/Instituto de Educação e Psicologia.

Touraine, A. (1999). Como sair do liberalismo?. Lisboa: Terramar.

Vincent, G., Lahire, B., \& Thin, D. (1994). Sur L’histoire et la théorie de la forme scolaire. In Guy Vincent (Dir.), L'éducation prisonnière de la forme scolaire? (pp. 11-48). Lyon: Presses Universitaires de Lyon.

Zablocki, B. (1980). Alienation and charisma: A study of contemporary American communes. New York: Free Press.

Submetido à análise em 07 de julho de 2016; revisado em 23 de maio de 2017; aceito para publicação em 04 de julho de 2017. 